\title{
As políticas de educação e o Plano Nacional de Educação (2014-2024): análise da materialização das propostas do plano
}

\section{Education policies and the National Education Plan (2014-2024): analysis of the materialization of the proposals of the plan}

Las políticas de educación y el Plan Nacional de Educación (2014-2024): análisis de la materialización de las propuestas del plan

\author{
Juliana Calabresi Voss Duarte ${ }^{1}$ \\ Claudinei Magno Magre Mendes ${ }^{1}$
}

DOI: http://dx.doi.org/10.20435/serie-estudos.v23i48.1124

\begin{abstract}
Resumo: O artigo apresenta reflexões acerca do atual Plano Nacional de Educação. Esse Plano configura-se como um documento resultante de uma política de Estado. As reflexões propostas buscam apresentar um panorama do processo de materialização de suas metas considerando os três primeiros anos de sua vigência. O Plano em estudo passou por um longo processo de estudos e reflexões, e uma das suas marcas foi a participação da sociedade civil na Conferência Nacional de Educação (CONAE) ocorrida em 2010. Essa Conferência, além de possibilitar um espaço de grande participação da sociedade política e civil, foi um momento de debate democrático que proporcionou a discussão dos rumos da educação brasileira. Pautado em pesquisas, documentos e autores, o estudo exibe uma breve análise dos principais marcos legais que contribuíram para o processo de elaboração da Lei 13.005/2014. Destaca ainda algumas fragilidades, limites e desafios do documento que norteia as ações destinadas ao campo da educação que prevê metas e estratégias a todos os níveis da educação brasileira. Nas análises, identifica-se a dificuldade de o plano avançar conforme previsto nas datas estabelecidas. Completado três anos de vigência da Lei supracitada, verifica-se que o proposto não se efetiva de acordo com as expectativas elencadas no documento.
\end{abstract}

Palavras-chave: Plano Nacional da Educação (PNE); metas e estratégias; políticas públicas educacionais.

\footnotetext{
${ }^{1}$ Universidade Estadual do Paraná (Unespar), Paranavaí, Paraná, Brasil.
} 
Abstract: The article presents reflections about the current National Education Plan. This Plan is configured as a document resulting from a State policy. The proposed reflections seek to present a panorama of the process of materialization of its goals considering the first three years of its validity. The Plan under study went through a long process of studies and reflections, and one of its marks was the participation of civil society in the National Conference of Education (CONAE) held in 2010. This Conference, besides making possible a space of great participation of society political and civil, was a moment of democratic debate that provided the discussion of the directions of Brazilian education. Based on research, documents and authors, the study presents a brief analysis of the main legal frameworks that contributed to the process of drafting Law 13,005 / 2014. It also highlights some weaknesses, limits and challenges of the document that guides actions aimed at the field of education that provides goals and strategies at all levels of Brazilian education. The analysis identifies the difficulty of the plan to advance as scheduled on the established dates. After three years of validity of the aforementioned Law, it is verified that the proposal does not comply with the expectations set forth in the document.

Keywords: National Education Plan (PNE); goals and strategies; public educational policies.

Resumen: El artículo presenta reflexiones acerca del actual Plan Nacional de Educación. Este Plan se configura como un documento resultante de una política de Estado. Las reflexiones propuestas buscan presentar un panorama del proceso de materialización de sus metas considerando los tres primeros años de su vigencia. El Plan en estudio pasó por un largo proceso de estudios y reflexiones, y una de sus marcas fue la participación de la sociedad civil en la Conferencia Nacional de Educación (CONAE) ocurrida en 2010. Esta Conferencia, además de posibilitar un espacio de gran participación de la sociedad política y civil, fue un momento de debate democrático que proporcionó la discusión de los rumbos de la educación brasileña. El estudio muestra un breve análisis de los principales marcos legales que contribuyeron al proceso de elaboración de la Ley 13.005 / 2014. Destaca aún algunas fragilidades, límites y desafíos del documento que orienta las acciones destinadas al campo de la educación que prevé metas y estrategias a todos los niveles de la educación brasileña. En los análisis se identifica la dificultad del plan avanzar según lo previsto en las fechas establecidas. Completado tres años de vigencia de la Ley arriba mencionada se verifica que el propuesto no se efectúa de acuerdo con las expectativas enumeradas en el documento.

Palabras clave: Plan Nacional de Educación (PNE); metas y estrategias; políticas públicas educativas.

\section{INTRODUÇÃO}

Após quase quatro anos de tramitação no Congresso, finalmente em 25 de junho de 2014, é aprovado o Plano Nacional de Educação (PNE), vigente no decênio 2014/2024. A Lei 13.005/2014 é aprovada a partir de muitas análises e discussões e é resultado de exigências constitucionais, assim como está previsto na Constituição Federal de 1988 e na Lei de Diretrizes e Bases da Educação de 1996.

Tomando como referência o Plano Nacional de Educação em vigência, o artigo propõe-se a refletir sobre o processo de discussão, elaboração e aprovação 
da Lei supracitada, bem como os encaminhamentos do processo de materialização das metas propostas até o terceiro ano de vigência.

Dada sua importância para a educação nacional é que se avulta a intenção do estudo dessa temática. As propostas contidas no documento tratam dos níveis e modalidades da educação brasileira, e sua elaboração é resultado de uma política pública destinada ao campo da educação. É a partir das diretrizes, metas e estratégias propostas no documento que muitos esforços deverão ser realizados para que este seja concretizado, nos prazos estabelecidos, com vistas à melhoria da educação brasileira.

A elaboração do Plano Nacional de Educação e a definição de suas diretrizes e estratégias de ação são resultado de mobilização social, ações do Ministério da Educação (MEC) e contribuições institucionais, como a Conferência Nacional de Educação (CONAE), o Conselho Nacional de Educação (CNE) e o Plano de Desenvolvimento da Educação (PDE). Nesse processo de elaboração do PNE, a Conferência Nacional de Educação (CONAE), ocorrida no ano de 2010 (BRASIL, 2010a), é destacada uma vez que esta se configura como um documento que impulsionou a elaboração do PNE 2014-2024.

O Plano Nacional de Educação (PNE) é visto como uma proposta ousada, porém necessária. Para sua materialização, os esforços deverão partir de todos os governos (União, Estados e Municípios) e da sociedade em geral. A agenda é desafiadora, principalmente se a realidade política e econômica do país na atualidade for levada em consideração. O corte de gastos em vários setores da sociedade- inclusive o da educação-, tornam a concretização do Plano ainda mais desafiador, pois muitas metas propostas demandam de investimentos no setor.

Com a abordagem dessa temática, espera-se que seja possível visualizar a situação atual em que se encontra o Plano Nacional de Educação em vigência no país, permitindo-se refletir sobre seus impactos para a educação brasileira bem como o processo de materialização e monitoramento do documento.

\section{DA DISCUSSÃO À APROVAÇÃO DO PNE}

Anteriormente à vigência do atual PNE (2014-2024), vigorou o Plano Nacional de Educação (2001-2010), que foi aprovado a partir da Lei n. 10.172, de 9 de janeiro de 2001. Com indicação da Constituição Federal (CF), o estabelecimento de um Plano Nacional de Educação passou a ter duração decenal. Partindo deste 
princípio- previsto no Art. 214 da Constituição- é que um novo Plano deveria passar a vigorar a partir do término do que estava em vigência (BRASIL, 1988, s.p.).

Contudo o PNE que deveria passar a vigorar a partir de 2011, ficou representado apenas pelo Projeto de Lei n. 8.035/2010 por mais de três anos. De acordo com Oliveira et al. (2011), este PL não considerou as decisões propostas na Conferência Nacional de Educação (CONAE) de 2010; assim os avanços contidos no documento final da CONAE não foram contemplados no Projeto de Lei, e respectivamente suas metas e estratégias não foram evidenciados em seu texto, conforme fora proposto pela Conferência.

O Projeto de Lei n. 8.035/10 foi apresentado à Presidência da República contendo vinte metas e 170 estratégias, além da Explanação de Motivos n. 033, que explicitava o processo de elaboração da proposta do PNE 2011-2020, relacionando-o com o Plano anterior (BRASIL, 2011, s.p.).

As discussões acerca do PNE que deveria passar a vigorar a partir de 2011, estenderam-se por muito tempo, e o número de emendas protocoladas ao texto original do PL totalizaram quase três mil, "fato nunca antes ocorrido em tramitação de matérias relativas à Educação no Congresso Nacional" (AQUINO, 2015, p. 63).

Os maiores entraves e discussões giraram em torno do financiamento da educação e quanto deveria ser destinado ao campo educacional. A partir das discussões e emendas acerca das propostas do Projeto de Lei n. 8.035/10, durante um bom limite de tempo, havia expectativas de que o projeto poderia sofrer vetos, ainda que o documento tivesse utilizado o tempo regimental limite para a sanção presidencial. No entanto, mesmo após reinvindicações de veto de dois trechos do PNE, este foi sancionado pela Câmara dos Deputados- sem vetos- no dia 25 de junho de 2014, convertendo-se na Lei n. 13.005/2014.

O Instituto Nacional de Estudos e Pesquisas Educacionais Anísio Teixeira (INEP), considera o atual Plano Nacional de Educação (PNE) como um documento orientador:

[...] define compromissos colaborativos entre os entes federativos e diversas instituições pelo avanço da educação brasileira. A agenda contemporânea de políticas públicas educacionais encontra no PNE uma referência para a construção e acompanhamento dos Planos de educação estaduais e municipais, o que o caracteriza como uma política orientadora para ações governamentais em todos os níveis federativos e impõe ao seu acompanhamento um alto grau de complexidade. (BRASIL, 2015, p. 11). 
O PNE é considerado por Saviani (2014a) como um instrumento importante para a educação brasileira e a principal medida de política educacional decorrente da Lei de Diretrizes e Bases (LDB/1996):

Resultado de imposição constitucional reiterada pela Lei de Diretrizes e Bases da Educação Nacional, o Plano Nacional da Educação emerge como o principal instrumento de desenvolvimento da educação brasileira. É, pois de fundamental importância compreender seu significado, alcance e limites no atual contexto brasileiro em articulação com a ainda pouco clara questão do sistema nacional da educação que deverá ser instituído, por lei específica, dois anos após a entrada em vigor do PNE. (SAVIANI, 2014a, p. 6).

Como resultado dessa imposição constitucional reiterada pela Lei de Diretrizes e Bases da Educação Nacional, o atual Plano Nacional de Educação (2014-2024) foi sancionado pela Presidenta Dilma Rousseff sob a Lei n. 13.005. Sua duração estende-se até 25 de junho de 2024, quando este completará dez anos de sua aprovação, devendo ser substituído por outro Plano, que deverá vigorar no período subsequente.

\section{PROCESSO DE MATERIALIZAÇÃO DAS PROPOSTAS DO PNE (2014-2024) ATÉ O TERCEIRO ANO DE VIGÊNCIA}

O Plano Nacional de Educação (2014-2024)- concretiza-se a partir da aprovação do texto-base do Projeto de Lei n. 8.035/10 (BRASIL, 2010b). No dia 25 de junho de 2014, a Lei n. 13.005 foi sancionada e está representada a partir de 14 artigos, 20 metas e 254 estratégias.

Vê-se na materialização da proposta de um Plano de Educação como sendo um meio para tentar corrigir um déficit histórico, que segundo Saviani (2000, s.p.) "nosso atraso já é, pois, secular [...]. E para enfrentar esse desafio, que há um século nos afronta, é mister assumir de vez a educação como prioridade de fato e não apenas nos discursos como ocorre recorrentemente".

De acordo com as diretrizes expressas no Art. 2o da Lei n. 13.005/2014, as 20 metas do PNE anunciam os desdobramentos que o documento deve seguir. As dez diretrizes orientadoras do Plano Nacional de Educação (PNE) expressam um nível de problematização a ser superado pela educação brasileira, que são observáveis nas diretrizes a seguir: 
I- erradicação do analfabetismo;

II- universalização do atendimento escolar;

III- superação das desigualdades educacionais, com ênfase na promoção da cidadania e na erradicação de todas as formas de discriminação;

IV- melhoria da qualidade da educação;

$\checkmark$ - formação para o trabalho e para a cidadania, com ênfase nos valores morais e éticos em que se fundamenta a sociedade;

VI- promoção do princípio da gestão democrática da educação pública;

VII- promoção humanística, científica, cultural e tecnológica do País;

VIII- estabelecimento de meta de aplicação de recursos públicos em educação como proporção do Produto Interno Bruto- PIB, que assegure atendimento às necessidades de expansão, com padrão de qualidade e equidade; IX- valorização dos (as) profissionais da educação;

X-promoção dos princípios do respeito aos direitos humanos, à diversidade e à sustentabilidade socioambiental. (BRASIL, 2014, s.p.).

Essas diretrizes assemelham-se às indicações postas pela Constituição Federal em seu Art. 214, que apresenta seis propósitos para melhorar a educação brasileira. Nessa nova proposta do PNE, as dez diretrizes em que se desmembra o PNE apresentam-se mais amplas, uma vez que incluem novos desafios a serem superados.

Os desafios elencados pela educação do país são verificáveis no estabelecimento das diretrizes e das metas. O Instituto Nacional de Estudos e Pesquisas Educacionais Anísio Teixeira (INEP), com base na Lei n. 13.005/2014, organizou-as em cinco grandes grupos que expõem diretrizes e metas do PNE.

\section{1) Diretrizes para a superação das desigualdades educacionais}

I - Erradicação do analfabetismo.

II - Universalização do atendimento escolar.

III - Superação das desigualdades educacionais, com ênfase na promoção da cidadania e na erradicação de todas as formas de discriminação.

Metas: de 1 a 5; 9; 11 e 12; 14.

\section{2) Diretrizes para a promoção da qualidade educacional}

IV - Melhoria da qualidade da educação.

V - Formação para o trabalho e para a cidadania, com ênfase nos valores morais e éticos em que se fundamenta a sociedade.

Metas: 6 e $7 ; 10 ; 13$. 


\section{3) Diretrizes para a valorização dos (as) profissionais da educação}

IX - Valorização dos(as) profissionais da educação.

Metas: 15 a 18.

\section{4) Diretrizes para a promoção da democracia e dos direitos humanos}

VI - Promoção do princípio da gestão democrática da educação pública.

VII - Promoção humanística, científica, cultural e tecnológica do País.

X - Promoção dos princípios do respeito aos direitos humanos, à diversidade e

à sustentabilidade socioambiental. Metas: 8 e 19.

\section{5) Diretrizes para o financiamento da educação}

VIII -Estabelecimento de meta de aplicação de recursos públicos em educação como proporção do Produto Interno Bruto (PIB), que assegure atendimento às necessidades de expansão, com padrão de qualidade e equidade.

Meta: 20.

A partir do estudo das vinte metas apresentada pelo Plano, é possível verificar a organização destas a partir das diretrizes apresentadas no Art. 2 do PNE. Nestas, há indicação de tempo (ano) e de quantidade (porcentagem) para que essas metas possam ser concretizadas, expressando a organicidade do documento.

As metas são possíveis de materializar-se por meio das estratégias que demandam ações provenientes dos entes federados, que darão os direcionamentos necessários e as responsabilidades aos setores competentes. A partir de sua configuração, tem-se, então, um Plano que possui uma organicidade capaz de conduzir as ações futuras da educação brasileira. Para atingir o alcance dessas intenções, é que o PNE se organiza em três grupos, definindo as diretrizes, as metas e as estratégias. A primeira diz respeito às grandes orientações, a segunda, aos objetivos quantificados, e a terceira, a ações a serem trilhadas.

O PNE que vigorou entre 2001-2010 foi alvo de muitas críticas e considerado como uma carta de intenções, pois, no período de sua vigência, este não conseguiu alcançar as metas propostas e também não representou as reais necessidades e reivindicações da sociedade civil. Em relação ao Plano anterior, Valente e Romano (2002), em suas análises, defenderam que o PNE de 2001/2010 não passou de uma carta de intenções, pois, na sua aprovação pelo Congresso, feriram-se o pensamento, as reivindicações e os desejos da comunidade escolar. Desse modo, 
não contemplou as propostas e reivindicações dos setores democráticos e populares da sociedade, mas o Brasil seguiu as orientações do Banco Mundial para os países subdesenvolvidos. Assim, "o PNE, como lei, de conjunto não contempla as propostas e reivindicações dos setores democráticos e populares da sociedade" (VALENTE; ROMANO, 2002, p. 106).

Um ponto frágil do PNE de 2001, considerado por Dourado (2010, p. 686), é que esse Plano - aprovado sob a Lei n. 10.172 - "não se constituiu como base e diretriz para políticas, planejamento e gestão da educação nacional nem foi acionado como tal pelos diferentes segmentos da sociedade civil e política brasileira". Não houve um acompanhamento da execução desse documento e não se efetivou uma avaliação sistemática e global do Plano e de sua concretização, também não houve movimento em defesa deste PNE, por entenderem que esse dispositivo legal não expressava o esforço político conduzido pela sociedade civil, e que, portanto, não se configurava como política de Estado, mas era resultante de manobras governamentais.

A partir do descontentamento expresso em relação ao PNE de 2001, muitas expectativas foram depositadas no Plano que estava para ser aprovado, pois este representava mais os anseios da sociedade em geral. A Conferência Nacional de Educação (CONAE/2010) foi um processo muito importante nessas discussões. Essa Conferência, além de possibilitar um espaço de grande participação da sociedade política e civil, foi um momento de debate democrático que proporcionou a discussão dos rumos da educação brasileira. O debate possibilitou reflexões desde a creche até a pós-graduação, e desta seria retirado "subsídios necessários à elaboração do Plano Nacional de Educação (PNE) para os próximos dez anos" (OLIVEIRA et al., 2011).

Contudo o Projeto de Lei n. 8.035/10 não tomou totalmente como referência as decisões elencadas pela Conferência para a elaboração da nova proposta do PNE.

Com a aprovação do PNE vigente, o foco recai sobre a materialização das propostas do documento, considerando que os problemas do primeiro Plano do século XXI não poderiam se repetir no segundo.

No corpo da Lei, há metas com prazos e percentuais estabelecidos a serem alcançados. O atual Plano contempla datas pré-estabelecidas para o alcance de algumas metas as quais são otimizadas por suas estratégias. Atualmente o Plano 
encontra-se no seu terceiro ano de vigência e, com isso, muitas metas já deveriam ter sido cumpridas desde o primeiro ano.

A partir do primeiro ano de vigência do Plano, houve a análise do seu panorama. Em 2015, quando o Plano em vigência completou um ano, o Deputado Federal Ivan Valente - PSOL/SP avaliou o período e, em relação ao documento, concluiu que o "Plano Nacional de Educação completa um ano e praticamente nada foi feito. Um ano perdido, um ano a menos para que se alcancem as metas nele estabelecidas".

Nessa avaliação, o deputado também ressaltou que, no decorrer do ano, nenhuma proposta se concretizou no prazo estabelecido, pois, em relação à taxa de analfabetismo no país, havia ao menos 8,7\% da população com 15 anos ou mais analfabeta, e outra grande parcela se mantinha no analfabetismo funcional. Levantou também que parte significativa dos Estados e Municípios não havia elaborado seus Planos de educação. Com a contenção de recursos, as metas do PNE ficaram ainda mais difíceis considerando que, para a efetivação destas, o orçamento deveria ter sido ampliado. Valente (2015, s.p.) concluiu, com a análise do primeiro ano do Plano, que além de ter sido um ano perdido, [...] é "também um alerta para toda sociedade civil para que não deixe que seja, ao longo da década, mais um PNE perdido".

O diagnóstico levantado em relação ao avanço do Plano não foi positivo, considerando que metas, objetivos e estratégias previstas para o período não foram alcançados, e os investimentos foram insuficientes.

Em junho de 2016, o PNE completou seu segundo ano de vigência, prevendo, também, o alcance de algumas metas. De acordo com a secretária executiva do Ministério da Educação (MEC), Maria Helena Guimarães de Castro, o Plano Nacional de Educação (PNE) ficou estagnado em 2016. Segundo ela, a meta que trata do financiamento (meta 20) é a base para as demais, e o contexto de crise fiscal atrapalhou o cumprimento das outras metas. Ainda de acordo com a secretária executiva, os investimentos no setor da educação diminuíram em vez de aumentar e, sem recursos disponíveis, não é possível melhorar a educação, considerando que as metas perpassam os níveis e modalidades da educação, passando pelo investimento, melhorias em infraestrutura e pela valorização do professor (TOKARNIA, 2016, s.p.). 
No ano de 2017, parceiros do Observatório do PNE (OPNE)² reuniram dados e lançaram um relatório contendo indicativos dos avanços do Plano Nacional de Educação que está em vigência. A seguir é apresentada resumidamente uma tabela contendo os artigos, as metas e as estratégias que deveriam ter sido cumpridos até o ano de 2017 e também apresenta a situação destas, ou seja, se foram cumpridas ou não. Assim expõe-se o retrato parcial do PNE em vigor:

\begin{tabular}{|c|c|c|c|}
\hline Artigos / Metas / Estratégias & Prazo & & Situação \\
\hline $\begin{array}{l}\text { Art. 5o, §2:: a cada } 2 \text { anos, a partir de } \\
\text { 2016, o INEP deverá publicar estudos } \\
\text { para aferir a evolução das metas. }\end{array}$ & 2016 & Cumprido & $\begin{array}{l}\text { Publicada a primeira } \\
\text { edição }\end{array}$ \\
\hline $\begin{array}{l}\text { Art. 8o: os Estados, o Distrito Federal } \\
\text { e os Municípios deverão elaborar seus } \\
\text { correspondentes Planos de Educação. }\end{array}$ & 2015 & $\begin{array}{c}\text { Parcialmente } \\
\text { cumprido }\end{array}$ & $\begin{array}{l}2 \text { estados e } 14 \text { municí- } \\
\text { pios ainda não sancio- } \\
\text { naram seus Planos }\end{array}$ \\
\hline $\begin{array}{l}\text { Art. 9o: leis específicas disciplinando a } \\
\text { gestão democrática da Educação pública } \\
\text { nos Estados, DF e Municípios. }\end{array}$ & 2016 & Não cumprido & $\begin{array}{l}\text { Não há iniciativas em } \\
\text { curso }\end{array}$ \\
\hline $\begin{array}{l}\text { Art. 10o: elaboração/aprovação do PPA } \\
\text { 2016-2019. }\end{array}$ & 2016 & $\begin{array}{c}\text { Sem } \\
\text { indicadores }\end{array}$ & Não é possível aferir \\
\hline $\begin{array}{l}\text { Art. 13o: estabelecimento do Sistema } \\
\text { Nacional de Educação em lei específica. }\end{array}$ & 2016 & Não cumprido & $\begin{array}{l}\text { Tramitação da propos- } \\
\text { ta parada }\end{array}$ \\
\hline $\begin{array}{l}\text { Meta 1: universalização da pré-escola } \\
\text { para as crianças de } 4 \text { e } 5 \text { anos. }\end{array}$ & 2016 & $\begin{array}{c}\text { Indicador não } \\
\text { atualizado }\end{array}$ & $\begin{array}{l}\text { Dados sugerem que } \\
\text { cumprimento é pos- } \\
\text { sível }\end{array}$ \\
\hline $\begin{array}{l}\text { 1.4: estabelecer normas, procedimentos } \\
\text { e prazos para definição de mecanismos } \\
\text { de consulta pública da demanda por } \\
\text { creches. }\end{array}$ & 2015 & Não cumprida & $\begin{array}{l}\text { Sem iniciativas em } \\
\text { curso }\end{array}$ \\
\hline $\begin{array}{l}\text { 1.6: implantar avaliação da Educação } \\
\text { Infantil, a ser realizada a cada } 2 \text { anos, } \\
\text { com base em parâmetros nacionais de } \\
\text { qualidade. }\end{array}$ & 2016 & Não cumprida & $\begin{array}{l}\text { Grupo de trabalho } \\
\text { criado, mas discus- } \\
\text { sões suspensas }\end{array}$ \\
\hline
\end{tabular}

\footnotetext{
${ }^{2}$ No Relatório intitulado de "3 anos de Plano Nacional de Educação" é possível ter acesso ao processo de materialização das metas e estratégias do atual PNE disponibilizado por meio de dados e análises.
} 
As políticas de educação e o Plano Nacional de Educação (2014-2024): análise da materialização das propostas do plano

\begin{tabular}{|c|c|c|c|}
\hline Artigos / Metas / Estratégias & Prazo & & Situação \\
\hline $\begin{array}{l}\text { 1.16: publicação de levantamento anual } \\
\text { da demanda manifesta por Educação } \\
\text { Infantil em creches e pré-escolas. }\end{array}$ & 2015 & Não cumprida & $\begin{array}{l}\text { IBGE fez levantamen- } \\
\text { to amostral sobre } \\
\text { demanda por creche, } \\
\text { ainda insuficiente }\end{array}$ \\
\hline $\begin{array}{l}\text { 2.1: Encaminhamento da proposta de di- } \\
\text { reitos e objetivos de aprendizagem e de- } \\
\text { senvolvimento do Ensino Fundamental. }\end{array}$ & 2016 & $\begin{array}{l}\text { Cumprida com } \\
\text { atraso }\end{array}$ & $\begin{array}{l}\text { MEC fez encaminha- } \\
\text { mento da } \\
\text { BNCC ao CNE }\end{array}$ \\
\hline $\begin{array}{l}\text { Meta 3: universalização do atendimento } \\
\text { escolar para toda a população de } 15 \text { a } \\
17 \text { anos. }\end{array}$ & 2016 & $\begin{array}{l}\text { Indicador não } \\
\text { atualizado }\end{array}$ & $\begin{array}{l}\text { Trajetória dos indica- } \\
\text { dores sugere que não } \\
\text { será cumprida }\end{array}$ \\
\hline $\begin{array}{l}\text { 3.2: encaminhamento da proposta de } \\
\text { direitos e objetivos de aprendizagem e } \\
\text { desenvolvimento para o Ensino Médio. }\end{array}$ & 2016 & Não cumprida & $\begin{array}{l}\text { Elaboração da BNCC } \\
\text { da etapa não foi con- } \\
\text { cluída }\end{array}$ \\
\hline $\begin{array}{l}\text { Meta 4: universalização do acesso à Edu- } \\
\text { cação básica e ao atendimento educa- } \\
\text { cional especializado para a população de } \\
4 \text { a } 17 \text { anos com deficiência. }\end{array}$ & 2016 & $\begin{array}{l}\text { Sem indicado- } \\
\text { res }\end{array}$ & $\begin{array}{l}\text { Informações dispo- } \\
\text { níveis sugerem não } \\
\text { cumprimento. Sem } \\
\text { iniciativas em curso }\end{array}$ \\
\hline $\begin{array}{l}\text { 4.14: definir indicadores de qualidade e } \\
\text { política de avaliação e supervisão para o } \\
\text { funcionamento de instituições públicas } \\
\text { e privadas que prestam } \\
\text { atendimento a alunos com deficiência. }\end{array}$ & 2016 & $\begin{array}{l}\text { Sem indicado- } \\
\text { res }\end{array}$ & $\begin{array}{l}\text { Sem iniciativas em } \\
\text { curso }\end{array}$ \\
\hline $\begin{array}{l}\text { Meta 7: fomentar a qualidade da Edu- } \\
\text { cação básica de modo a atingir metas } \\
\text { nacionais para o Ideb. }\end{array}$ & 2015 & $\begin{array}{l}\text { Parcialmente } \\
\text { cumprida }\end{array}$ & $\begin{array}{l}\text { Apenas a meta do } 50 \\
\text { ano do Ensino Funda- } \\
\text { mental foi cumprida }\end{array}$ \\
\hline $\begin{array}{l}\text { 7.10: fixar, acompanhar e divulgar bie- } \\
\text { nalmente os resultados pedagógicos dos } \\
\text { indicadores educacionais assegurando a } \\
\text { contextualização em relação a indicado- } \\
\text { res sociais relevantes e a transparência e } \\
\text { o acesso público às informações. } \\
\end{array}$ & 2016 & Cumprida & $\begin{array}{l}\text { Embora precise de } \\
\text { aprimoramento, inicia } \\
\text { tivas foram tomadas e } \\
\text { indicadores têm sido } \\
\text { divulgados com maior } \\
\text { contextualização } \\
\end{array}$ \\
\hline $\begin{array}{l}\text { 7.21: Parâmetros mínimos de qualidade } \\
\text { dos serviços da Educação básica. }\end{array}$ & 2016 & Não cumprida & Depende da BNCC \\
\hline $\begin{array}{l}\text { Meta 9: elevar a taxa de alfabetização } \\
\text { da população com } 15 \text { anos ou mais para } \\
93,5 \% \text { até } 2015 \text {. }\end{array}$ & 2015 & Não cumprida & $\begin{array}{l}\text { Políticas existentes } \\
\text { são insuficientes }\end{array}$ \\
\hline
\end{tabular}




\begin{tabular}{|c|c|c|c|}
\hline Artigos / Metas / Estratégias & Prazo & & Situação \\
\hline $\begin{array}{l}\text { Meta 15: garantir política nacional de } \\
\text { formação dos profissionais da Educação, } \\
\text { assegurando que todos os professores } \\
\text { da Educação básica possuam formação } \\
\text { específica de nível superior (licenciatura) } \\
\text { na área de conhecimento em que atuam. }\end{array}$ & 2015 & Não cumprida & $\begin{array}{l}\text { Não há política articu- } \\
\text { ladas com entes fe- } \\
\text { derados. O que há de } \\
\text { política de formação } \\
\text { para o magistério, não } \\
\text { possui indicadores }\end{array}$ \\
\hline $\begin{array}{l}\text { 15.11: política nacional de formação } \\
\text { continuada para os profissionais da Edu- } \\
\text { cação que não os do magistério, cons- } \\
\text { truída em regime de colaboração } \\
\text { entre os entes federados. }\end{array}$ & 2015 & Não cumprida & $\begin{array}{l}\text { Não há política para } \\
\text { formação dos profis- } \\
\text { sionais da Educação } \\
\text { que não sejam do } \\
\text { magistério }\end{array}$ \\
\hline $\begin{array}{l}\text { 17.1: constituir fórum permanente de } \\
\text { acompanhamento do piso salarial nacio- } \\
\text { nal do magistério público da Educação } \\
\text { básica. }\end{array}$ & 2015 & Cumprida & Fórum constituído \\
\hline $\begin{array}{l}\text { Meta 18: assegurar a existência de Pla- } \\
\text { nos de carreira para os profissionais } \\
\text { da Educação básica e superior pública } \\
\text { tomando como referência o piso salarial } \\
\text { nacional profissional. }\end{array}$ & 2016 & Não cumprida & $\begin{array}{l}\text { Sem iniciativas em } \\
\text { curso em } \\
\text { âmbito federal. Indica- } \\
\text { dores insuficientes. }\end{array}$ \\
\hline $\begin{array}{l}\text { 18.1: estruturar as redes de ensino para } \\
\text { garantir que no mínimo } 90 \% \text { dos profis- } \\
\text { sionais do magistério e } 50 \% \text { dos profis- } \\
\text { sionais da Educação não docentes sejam } \\
\text { ocupantes de cargos efetivos nas redes } \\
\text { escolares a que se encontrem vinculados. }\end{array}$ & 2017 & Não cumprida & $\begin{array}{l}\text { Não há iniciativas } \\
\text { em curso em âmbito } \\
\text { nacional para apoiar } \\
\text { a estruturação das } \\
\text { redes de ensino nesse } \\
\text { sentido }\end{array}$ \\
\hline $\begin{array}{l}\text { 18.3: realizar a cada } 2 \text { anos prova nacio- } \\
\text { nal para subsidiar os Estados, o Distrito } \\
\text { Federal e os Municípios, mediante ade- } \\
\text { são, na realização de concursos públicos } \\
\text { de admissão de profissionais do magis- } \\
\text { tério da Educação básica pública. } \\
\end{array}$ & 2016 & Não cumprida & $\begin{array}{l}\text { Debate já esteve pre- } \\
\text { sente no } \\
\text { MEC, mas atualmente } \\
\text { não há iniciativas em } \\
\text { curso. }\end{array}$ \\
\hline $\begin{array}{l}\text { 18.5: realizar anualmente o censo dos } \\
\text { profissionais da Educação básica de ou- } \\
\text { tros segmentos que não os do magistério. }\end{array}$ & 2015 & Não cumprida & $\begin{array}{l}\text { Não há informações } \\
\text { de que o censo tenha } \\
\text { sido realizado }\end{array}$ \\
\hline $\begin{array}{l}\text { Meta 19: garantia de condições para } \\
\text { a efetivação da gestão democrática da } \\
\text { Educação. }\end{array}$ & 2015 & $\begin{array}{c}\text { Sem indicado- } \\
\text { res }\end{array}$ & $\begin{array}{l}\text { Sem iniciativas em } \\
\text { curso em âmbito na- } \\
\text { cional }\end{array}$ \\
\hline
\end{tabular}


As políticas de educação e o Plano Nacional de Educação (2014-2024): análise da materialização das propostas do plano

\begin{tabular}{|c|c|c|c|}
\hline Artigos / Metas / Estratégias & Prazo & & Situação \\
\hline $\begin{array}{l}\text { 20.6: implantação do Custo Aluno-Quali- } \\
\text { dade inicial (CAQi), que será progressiva- } \\
\text { mente reajustado até a implementação } \\
\text { plena do Custo Aluno. }\end{array}$ & 2016 & Não cumprida & $\begin{array}{l}\text { Há um parecer do } \\
\text { CNE, não homologado } \\
\text { pelo MEC. Debate pre- } \\
\text { sente, mas com pou- } \\
\text { cas ações concretas }\end{array}$ \\
\hline $\begin{array}{l}\text { 20.8: o CAQ será definido no prazo de } 3 \\
\text { anos e será continuamente ajustado. }\end{array}$ & 2017 & Não cumprida & Idem 20.6 \\
\hline $\begin{array}{l}\text { 20.9: estabelecer as normas de coopera- } \\
\text { ção entre a União, os Estados, o Distrito } \\
\text { Federal e os Municípios e a articulação } \\
\text { do sistema nacional de } \\
\text { Educação em regime de colaboração. }\end{array}$ & 2016 & Não cumprida & $\begin{array}{l}\text { Debate presente, mas } \\
\text { com poucas ações } \\
\text { concretas. }\end{array}$ \\
\hline $\begin{array}{l}\text { 20.11: aprovar Lei de Responsabilidade } \\
\text { Educacional. }\end{array}$ & 2015 & $\begin{array}{l}\text { Em andamen- } \\
\text { to }\end{array}$ & $\begin{array}{l}\text { Há proposta em tra- } \\
\text { mitação na } \\
\text { Câmara, mas não } \\
\text { avança }\end{array}$ \\
\hline
\end{tabular}

Fonte: Relatório do Observatório do PNE: 3 anos de Plano Nacional de Educação.

A partir do panorama apresentado, percebe-se infelizmente certo descompasso entre o proposto e o efetivado. Muitas metas que deveriam estar materializadas, não estão, e o fato gera uma decepção para a sociedade brasileira na medida em que se espera que as metas e estratégias traçadas saiam do papel e sejam executadas e monitoradas.

Entre o rol de objetivos, metas, artigos e estratégias a serem alcançados até o ano de 2016, é dado destaque ao cumprimento da implementação de um fórum permanente de acompanhamento do valor do piso salarial dos professores (estratégia 17.1 da meta 17). Esse objetivo estava previsto para ser cumprido até o final do primeiro ano de vigência deste PNE, ou seja, no ano de 2015.

Entre as estimativas do alcance de metas até o segundo ano do plano, a inclusão de todas as crianças de 4 a 5 anos na escola até o momento é apenas mais uma estratégia não alcançada, pois dados disponíveis indicam que 10,4\% dessa faixa etária estão fora da educação infantil, conforme salienta a secretária executiva do Ministério da Educação (MEC). Outra meta descumprida que a secretária destacou é a definição do Sistema Nacional de Educação- item previsto no art. 13 da Lei 13.005/2014. 
A meta 3 também está comprometida e, até o momento, está apenas no papel. De acordo com alguns dados, há ainda 1,7 milhão de pessoas na faixa etária de 15 a 17 anos sem atendimento escolar, comprometendo assim a universalização do ensino para esses adolescentes. De acordo com Daniel Cara - coordenador da Campanha Nacional pelo Direito à Educação (CNDE) -, "o governo federal não pode considerar o PNE um fardo, desde 2014 muito mais deveria ter sido feito" (FERREIRA, 2016, s.p.).

Priscila Cruz, presidente-executiva do Todos Pela Educação, demonstra-se mais otimista e diz que essas notícias negativas não podem desanimar as autoridades envolvidas no cumprimento das metas:

Enquanto não houver um trabalho estruturante, corremos o risco de ter, ano após ano, as metas não cumpridas. O plano é ambicioso, mas grande parte dele é realizável, não podemos desmobilizar. As 15 primeiras metas têm responsabilidade de estados e municípios e só vamos conseguir alcançá-las com um trabalho bem gerido. (FERREIRA, 2016, s.p.).

Outro destaque também é dado à meta 15 que também previa alcance a partir de um ano de vigência do plano. Nesta, almejava-se a implementação de política de formação para professores da educação básica, a qual ainda não foi concluída. De acordo com os dados apresentados pelo Observatório do PNE, ainda há um percentual considerável de professores sem formação em nível superior. "Dos 2,2 milhões de docentes que atuam na Educação Básica do país, aproximadamente $24 \%$ não possuem formação de nível superior [...]" (OBSERVATÓRIO DO PNE, 2017a, s.p.).

Em 2015, segundo dados disponibilizados também pelo Observatório do PNE (2017a), 76,4\% dos professores da Educação Básica possuíam curso superior; 45,9\% dos docentes dos anos finais do Ensino Fundamental possuíam formação superior na área em que lecionam, e 53,8\% dos docentes do Ensino Médio com formação superior, na área em que lecionam. A meta desejada é que se alcancem 100\% de professores com formação específica até 2024.

Conforme previsto no Art. 5 da Lei 13.005/2014, a execução do PNE e o cumprimento de suas metas serão objeto de monitoramento contínuo e de avaliações periódicas. Contudo há indicativos de que o monitoramento a ser realizado pelo Ministério da Educação (MEC), pela Comissão de Educação da Câmara dos Deputados e Comissão de Educação, Cultura e Esporte do Senado Federal, pelo 
Conselho Nacional de Educação (CNE) e pelo Fórum Nacional de Educação (FNE) não está ocorrendo satisfatoriamente.

De acordo com o Relatório do Observatório do PNE (2017b), "A falta de mecanismos de monitoramento pode provocar um distanciamento dos propósitos do Plano. Sem um acompanhamento contínuo e documentado, no final só restará apontar os problemas que impediram alcançar os resultados esperados". O atual Plano não pode acabar fracassado como o Plano anterior, que ficou sem alcançar suas metas por falta de prioridade no setor educacional.

A educação brasileira possui uma trajetória histórica marcada por processos fragmentados. O Brasil possui um percurso de propostas visando ao êxito educacional, porém nem sempre este é colocado como prioridade nas ações governamentais. O desafio decorre em efetivar as propostas das políticas educativas e colocá-las como medidas prioritárias.

Sobre esse processo de fragmentação expresso pelas políticas de governo e não de Estado, Oliveira (2011) destaca que:

Ao final do governo FHC, é possível considerar que a educação nacional se encontrava em um quadro de (des) sistematização, para designar uma orientação de governo na contramão do que se pode considerar um sistema, ou seja, uma organização da educação nacional fragmentada, segmentada, flexível e dispersa, o que não contribui para estabelecer bases de cooperação, integração e coesão entre os entes federativos e menos ainda entre os indivíduos na sociedade. (OLIVEIRA, 2011, p. 327).

Nessa conjuntura de falta de prioridades e processos fragmentados, Dourado (2016) considera que o PNE configura-se como um projeto que se situa nas políticas educacionais:

Nesta complexa seara, situam-se as políticas educacionais, especialmente o PNE 2014-2024 e sua importância política e estratégica. O Plano, aprovado em 2014, após vários tensionamentos, deve constituir o eixo das políticas educativas. Desse modo, os principais desafios atuais referem-se ao processo de materialização do PNE ao qual se articulam as condições objetivas, econômicas e políticas das concepções em disputa e a necessária regulamentação de algumas de suas metas e estratégias, bem como um efetivo esforço de ampliação dos recursos para a educação. (DOURADO, 2016, p. 20).

Assim, a concretização da proposta do estabelecimento de um Sistema Nacional de Educação (SNE) e a materialização das metas estabelecidas no Plano 
Nacional de Educação precisa constituir-se de uma política de Estado possibilitando condições e prioridades para que se possa avançar na área educacional.

No descompasso entre o proposto e o efetivado, percebe-se que muitos esforços ainda precisam ser intensificados para que se alcancem as propostas. Muitas crianças e adolescentes ainda se encontram sem atendimento escolar, alguns estados e municípios ainda não possuem seus Planos de educação aprovados, há ausência de Planos de carreira em alguns lugares, pouco investimento no setor educacional entre outros pontos que prejudicam o avanço e desenvolvimento educacional do país.

\section{CONSIDERAÇÕES FINAIS}

A partir das dificuldades e dos vetos sofridos no PNE de 2001/2010, sua efetivação ficou comprometida, ficando marcado como uma carta de intenções. Houve uma proposição no plano, porém este não se efetivou. Em 2010, o governo lançou a proposta do atual PNE que ficou por mais ou menos quatro anos em tramitação.

O Plano Nacional de Educação de 2014 é resultado de discussões que trouxeram à tona os problemas evidenciados pela educação brasileira. Esse plano prevê superar as deficiências que se acumulam historicamente: erradicar o analfabetismo, universalizar o atendimento escolar, superar as desigualdades educacionais, melhorar a qualidade da educação, formar o estudante para o trabalho e para a cidadania, promover o princípio da gestão democrática, estabelecer meta de aplicação de recursos públicos em educação, valorizar os profissionais da educação, promover os princípios do respeito aos direitos humanos, à diversidade e à sustentabilidade socioambiental.

Objetivando obter uma visão do processo de efetivação- ainda que parcial, pode-se visualizar como está o percurso desse documento expresso pela Lei n. $13.005 / 2014$.

Se fizermos um comparativo de evolução da educação brasileira nos últimos anos, é notável a melhora desta, mesmo considerando que possuímos um déficit histórico se comparado este ao outros países. Contudo poderíamos ter evoluído mais, se o sistema ao qual pertencemos não fosse refém de alguns interesses particulares. Outro ponto a ser destacado é o espaço geográfico do país. Existe uma dimensão territorial muito extensa, e o fato agrava ainda mais as disparidades por regiões. As desigualdades entre as regiões, em termos educacionais, 
ficam evidenciadas na análise de alguns relatórios (Relatório de Monitoramento do PNE; Relatório do Observatório do PNE). Mediante a constatação da falta de concretização de muitas metas do PNE anterior é que o atual Plano Nacional de Educação continuou prevendo as mesmas metas. Porém, se ficarmos apenas adiando as ações, os problemas enfrentados pela educação brasileira serão somente protelados.

$\mathrm{Na}$ análise dos dados apresentados, avançamos pouco em relação à materialização das propostas das metas nos prazos estabelecidos, e, paralelamente a esta morosidade no processo de efetivação, tem-se também um outro agravante no campo educacional, que é o corte de investimentos na área, que está claramente expresso pela PEC 055/2016, implicando, segundo Azevedo (2016, p. 256) "em favor da austeridade fiscal por duas décadas (até 2036), [...] na corrosão da sustentabilidade financeira de variados programas de seguridade social e de políticas públicas no País, inclusive na impossibilidade do cumprimento do Plano Nacional de Educação - PNE (2014-2024)".

Com o Novo Regime Fiscal (NRF), há um descontentamento social, pois aquele limita investimentos no país, e a área educacional, em vista das propostas do PNE, fica comprometida, pois as metas para serem alcançadas precisam de investimentos no setor. Mais uma vez a impressão que temos é que interesses das classes dominantes estão no topo das prioridades nacionais.

A história da educação brasileira caracteriza-se como um processo marcado por disputas de projetos com concepções distintas acerca do papel do Estado. Em geral as propostas decorrentes do campo educacional estiveram e ainda estão a serviço de grupos com interesses próprios. Graças à influência de alguns grupos interessados na melhoria da educação do país e, consequentemente, com a proposta de instituição de um Plano de Educação, é que ocorreram mobilizações e propostas com o intuito de colocar, como foco principal na sociedade, a educação brasileira. O fato demonstra certo progresso em relação às prioridades no setor educacional.

Contudo o Plano em vigência, assim como o anterior, possui pontos frágeis que Ihe comprometem a efetivação. Saviani (2014b) considera que o PNE (2014), ao excluir considerações relativas ao diagnóstico, tornou-se frágil:

[...] a ausência do diagnóstico também torna o plano frágil. Isso porque o diagnóstico, enquanto caracterização da situação com seus limites e carências, fornece a base e a justificativa para o enunciado das metas que 
compõem o plano a ser executado. Sem ele, várias das metas resultam arbitrárias, não se entendendo, por exemplo, porque se pretende "elevar a taxa de alfabetização da população com 15 anos ou mais para 93,5\% até 2015 e erradicar, até 2020, o analfabetismo absoluto e reduzir em $50 \%$ a taxa de analfabetismo funcional [...]. O diagnóstico nos permitiria entender a razão desses números. Sem ele ficamos sem saber por que se fixou a meta de $50 \%$ e não, por exemplo, em 40 ou 60\%. (SAVIANI, 2014b, p. 84)

O autor ainda destaca que esse plano deveria ter sido realizado a partir de revisão cuidadosa do PNE de 2001-2010, refazendo, assim, o diagnóstico das necessidades educacionais.

Davies (2014), ao tratar do financiamento da educação, previsto na meta 20 do PNE (2014-2024), considera que este possui várias fragilidades, pois não é mencionado no corpo da Lei quanto deverá ser investido em educação 'entre' alguns períodos de tempo:

O financiamento contém vários pontos fracos. Um é que a Lei prevê no mínimo $10 \%$ do PIB para o final da vigência do PNE, ou seja, 10 anos a contar de 2014, sendo no mínimo 7\% do PIB no quinto ano, a saber, em 2019. Como não definição de percentuais e progressividade entre estes períodos, o Poder Público não é obrigado a aplicar nenhum percentual durante eles. Em outras palavras, até o quarto ano não há nenhuma exigência de percentual, assim como do 60 até o 9․ De qualquer modo, estes $10 \%$ foram um avanço em relação aos 7\% previstos no PL-governo de 2010. (DAVIES, 2014, p. 198).

Outro ponto destacado por Davies (2014) é em relação à destinação dos recursos para a educação pública que, aparentemente, se vinculam ao público. Entretanto esses investimentos públicos poderão ser destinados a programas que beneficiam instituições privadas como o FIES (Fundo de Financiamento ao Estudante do Ensino Superior Privado) e o PROUNI (Programa Universidade Para Todos), conforme consta em algumas estratégias ${ }^{3}$ da meta 12 do PNE de 2014.

\footnotetext{
${ }^{3}$ As estratégias que tratam da destinação do recurso ao setor privado são: 12.6) expandir o financiamento estudantil por meio do Fundo de Financiamento Estudantil (FIES), de que trata a Lei n. 10.260, de 12 de julho de 2001, com a constituição de fundo garantidor do financiamento, de forma a dispensar progressivamente a exigência de fiador; 12.20) ampliar, no âmbito do Fundo de Financiamento ao Estudante do Ensino Superior- FIES, de que trata a Lei n. 10.260, de 12 de julho de 2001, e do Programa Universidade para Todos (PROUNI), de que trata a Lei n.11.096, de 13 de janeiro de 2005, os benefícios destinados à concessão de financiamento a estudantes regularmente matriculados em cursos superiores presenciais ou a distância, com avaliação positiva, de acordo com regulamentação própria, nos processos conduzidos pelo Ministério da Educação.
} 
Mesmo com indícios de que não estamos evoluindo de forma satisfatória de acordo com os prazos estabelecidos pelo PNE de 2014, depositam-se nesse documento algumas expectativas de que a educação nacional poderá melhorar em termos qualitativos. O plano prevê que sua execução e seu cumprimento serão objeto de monitoramento contínuo e de avaliações periódicas, devendo as instâncias responsáveis por esse processo divulgar os resultados do monitoramento e das avaliações em sítios institucionais da internet. Assim, tanto a comunidade civil quanto a escolar pode acompanhar a evolução do PNE que deverá estar à disposição para consulta pública. Nesse sentido, todos são chamados a acompanhar esse processo, bem como reivindicar pela concretização das suas propostas.

\section{REFERÊNCIA}

AQUINO, L. M. S. Formulação do Plano Nacional de Educação 2014-2024: a gestão democrática da escola na política pública. 2015. Tese (Doutorado em Educação)- Universidade Federal do Rio Grande do Sul. Porto Alegre, RS, 2015.

AZEVEDO, M. L. N. O novo regime fiscal: a retórica da intransigência, o constrangimento da oferta de bens públicos e o comprometimento do PNE 2014-2024. Tópicos Educacionais, Recife, v. 22, n. 1, jan./jun. 2016.

BRASIL. Instituto Nacional de Estudos e Pesquisas Educacionais Anísio Teixeira. Plano Nacional de Educação PNE 2014-2024: Linha de Base. Brasília, DF: Inep, 2015.

. Lei n. 13.005, de 25 de junho de 2014. Aprova o Plano Nacional de Educação (PNE) e dá outras providências. Diário Oficial [da] República Federativa do Brasil. Poder Executivo, Brasília, DF, 26 jun. 2014, Seção 1. Ed. Extra, p. 1. 2014.

. Projeto de Lei do Plano Nacional da Educação (PNE 2011-2020). Brasília, 2011. Disponível em: < http://bd.camara.gov.br/bd/handle/bdcamara/5826>. Acesso em: 16 dez. 2017. MEC, 2010a.

. Conferência Nacional de Educação (CONAE). Documento final da Conae. Brasília:

. Projeto de Lei n. 8.035/2010b. Aprova o Plano Nacional de Educação para o decênio 2011-2020 e dá outras providências. Brasília, 2010. Disponível em: <http:// bd.camara.gov.br/bd/handle/bdcamara/5826>. Acesso em: 16 dez. 2017.

. Lei n. 10.172, de 9 de Janeiro de 2001. Aprova o Plano Nacional de Educação (2001-2010) - PNE e dá outras providencias. Diário Oficial da União, Brasília, DF, 10 jan. 2001. Disponível em:<http://www.planalto.gov.br/ccivil_03/leis/leis_2001/l10172.htm>. 
. Constituição (1988). Constituição da República Federativa do Brasil. Brasília, DF: Senado, 1988. Disponível em: <http://www.planalto.gov.br/ccivil_03/constituicao/ ConstituicaoCompilado.htm>. Acesso em: 20 dez. 2017.

DAVIES, N. Fragilidades e desafios do financiamento em planos de educação: 10\% do PIB são a salvação? In: SOUZA, Donaldo Bello de; MARTINS, Ângela. Maria (Org.). Planos de educação no Brasil: planejamentos, políticas, práticas. São Paulo: Loyola, 2014. p. 183-205.

DOURADO, L. F. Plano Nacional de Educação: política de estado para a educação brasileira. Brasília: Inep, 2016. (PNE em Movimento). ISSN 2448-4288.

. Avaliação do Plano Nacional de Educação 2001-2009: questões estruturais e conjunturais de uma política. Educação e Sociedade, v. 31, n. 112, p. 677-705, 2010. ISSN 0101-7330.

FERREIRA, P. O Globo. País não cumpre metas do Plano Nacional da Educação para 2016. 2016. Disponível em:<https://oglobo.globo.com/sociedade/educacao/pais-nao-cumpre-metas-do-plano-nacional-da-educacao-para-2016-19604817>. Acesso em: 4 jan. 2018.

OBSERVATÓRIO DO PNE. Metas do PNE. 2017a. Disponível em: <http://www.observatoriodopne.org.br/metas-pne>. Acesso em: 5 jan. 2018.

. 3 Anos de Plano Nacional de Educação. 2017b. Disponível em: <http://www. observatoriodopne.org.br/uploads/reference/file/673/documento-referencia.pdf $>$. Acesso em : 9 jan. 2018.

OLIVEIRA, D. A. Das políticas de governo à política de estado: reflexões sobre a atual agenda educacional brasileira. Educação e Sociedade, Campinas, v. 32, n. 115, p. 32337, abr./jun. 2011.

OLIVEIRA, D. A et al. Por um Plano Nacional de Educação (2011-2020) como política de Estado. Revista Brasileira de Educação, Rio de Janeiro, v. 16, n. 47, maio/ago. 2011.

SAVIANI, D. Plano Nacional da Educação PNE 2014-2024. Teor integral conforme edição extra do Diário Oficial da União de 26/06/2014. Campinas. Autores Associados, 2014a.

. Sistema Nacional de Educação e Plano Nacional de Educação. Campinas: Autores Associados, 2014b.

. Educação no Brasil: concepção e desafios para o Século XXI. Revista Histedbr On-line, Campinas, 2000. Disponível em: <http://www.histedbr.fe.unicamp.br/revista/ revis/revis03/art1_3.html>. Acesso em: 7 nov. 2017.

TOKARNIA, M. Crise fiscal atrapalhou cumprimento do PNE, diz secretária executiva do MEC. Agência Brasil. nov. 2016. Disponível em: <http://agenciabrasil.ebc.com.br/ educacao/noticia/2016-11/investimento-em-educacao-cai-desde-2015-diz-secretaria-executiva-do-mec>. Acesso em: 1o dez. 2017. 
VALENTE, I. PNE completa um ano e não saiu do papel. 2015. Disponível em: <http:// www.ivanvalente.com.br/pne-completa-um-ano-e-nao-saiu-do-papel/>. Acesso em: 3 nov. 2017.

VALENTE, I.; ROMANO, R. PNE: Plano Nacional de Educação ou carta de intenção? Educação e Sociedade, Campinas, v. 23, n. 80, p. 96-107, set. 2002.

\section{Sobre os autores:}

Juliana Calabresi Voss Duarte: Graduação em Pedagogia pela Faculdade de Ciências e Letras de Paranavaí (FAFIPA). Mestre em Educação pela Universidade Estadual do Paraná (UNESPAR). Professora da Rede Estadual de Educação (SEED). E-mail: ju.llia@hotmail.com

Claudinei Magno Magno Magre Mendes: Graduação em História pela Universidade Estadual Paulista (UNESP). Mestre em História Social e doutor em História Social pela Universidade de São Paulo (USP). Professor do corpo permanente do PPIFOR - Mestrado em Ensino: Formação Docente Interdisciplinar da Universidade Estadual do Paraná (UNESPAR), Paranavaí. E-mail: mendes.claudinei@gmail.com

\section{Recebido em janeiro de 2018}

Aprovado em março de 2018 
